\title{
Research on Chinese Processing Trade and Its Related Factors
}

\author{
Boyang Sun \\ School of International Trade and Economics, University of International Business and Economics, 100029, \\ Beijing, China
}

Keywords: Processing trade, Chinese economy, International cooperation

\begin{abstract}
Processing trade is one of the most important sources of trade in China. On January 18, 2016, The Chinese State Council issued "several proposals on promoting the development of processing trade”, indicating that nowadays Chinese government has paid lots of attention on upgrading the processing trade in China. In consideration of this, the paper will mainly focus on how to develop Chinese processing trade, analyzing factors that may influence the promotion of processing trade, thus give some suggestions on how to transform or upgrade the processing trade effectively and efficiently concerning specific economical conditions in China.
\end{abstract}

\section{Introduction}

Processing trade is one of the most important sources of trade in China. On January 18, 2016, The Chinese State Council issued "several proposals on promoting the development of processing trade", indicating that nowadays Chinese government has paid lots of attention on upgrading the processing trade in China. In consideration of this, the paper will mainly focus on how to develop Chinese processing trade, analyzing factors that may influence the promotion of processing trade, thus give some suggestions on how to transform or upgrade the processing trade effectively and efficiently concerning specific economical conditions in China.

Some scholars have discovered factors that affect the development of processing trade. According to the new Trade Theory (Krugman, 1980), increasing returns to scale (IRS) is the source of gains from trade, so the value-added ratio of processing trade should be positively correlated to its scale. Feenstra (1996) stated that foreign direct investment (FDI) would benefit processing trade in developing countries. Gereffi (1999) found that with the enrichment of factor endowments and the rise in the productivity of local firms, comparative advantages would appear in high value-added production chains, resulting in the promotion of processing trade. Harrigan, Venables (2004) presented that the spatial location of producers and the development of local transportation played important roles in processing trade. Ming Zhang, Bing Hu (2010) found that low R\&D investment and human capital were crucial constraints for the development of processing trade in China. Qinglin Zhang (2011) discovered that FDI had more pros than cons on Chinese processing trade, because spillover effects were larger than crowd-out effects. Gui Zeng (2011) presented that the study effects and innovation would benefit processing trade in the long run by placing domestic firms on a higher global value chain (GVC).

However, empirical studies including the above factors are rather few or incomplete in China. Zhongdi Zhu (2007) used country-level data from 1996 to 2005 to analyze the effects of factors on Chinese processing trade, but he failed to consider the regional differences and the serial correlation problem. Ming Zhang (2010) used country-level data from 1981 to 2007 to do econometrical analysis on Chinese processing trade, but he failed to get a province-level sample (which is larger) and did not include enough essential variables in the regression (which would cause omitted variable bias).

As a result, compared with the above literature, this paper has four main contributions:

(1) Include all the factors or variables mentioned above to lower omitted variable bias.

(2) Use province-level panel data with the Two-Stage Least Squares methodology to deal with endogeneity and simultaneous causality problem.

(3) Use large and updated observations to get robust estimations. 
(4) Consider the regional differences in the development of processing trade in China and test their significance by adding regional dummy variables into the Random Effects Model.

\section{Model and Data}

To further analyze factors that may influence the development of Chinese processing trade, I managed to collect a panel data set with 31 provinces in China from year 2003 to 2015 included. Then based on the review of literature, I set up a model concerning the estimation on specific effects of the variables involved.

$$
\begin{gathered}
\log \left(\text { valueadd }_{\text {it }}\right)=\beta_{0}+\beta_{1} \log \left(\text { patent }_{\text {it }}\right)+\beta_{2} \log \left(\mathrm{FDI}_{\mathrm{it}}\right)+\beta_{3} \log \left(\mathrm{TFP}_{\mathrm{it}}\right)+ \\
\beta_{4} \log \left(\mathrm{FDI}_{\mathrm{it}}\right) * \log \left(\mathrm{TFP}_{\mathrm{it}}\right)+\beta_{5} \log \left(\text { wage }_{\mathrm{it}}\right)+\beta_{6} \log \left(\text { graduate }_{\mathrm{it}}\right)+ \\
\beta_{7} \text { transport }_{\text {it }}+\beta_{8} \text { east }_{\mathrm{i}}+\beta_{9} \text { mid }_{\mathrm{i}}+\mathrm{a}_{\mathrm{i}}+\mathrm{u}_{\mathrm{it}}
\end{gathered}
$$

\section{Analysis and Results}

To further analyze factors that may influence the development of Chinese processing trade, I managed to collect a panel data set with 31 provinces in China from year 2003 to 2015 included. Then with the help of Eviews9.0, I conducted a random effects model with Two-Stage Least Squares methodology, and got the following regression results:

$\log ($ valueaddit $)=-4.224+0.084 \log$ (patentit) $+0.257 \log$ (FDIit) $+1.033 \log ($ TFPit $)$

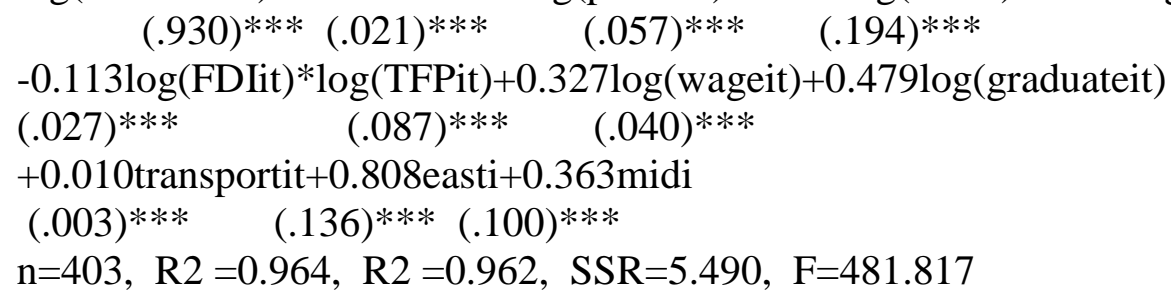

Firstly, some necessary statistical tests should be employed and the results are shown as below:

(1) Hausman's test for random effects model. To make sure that a random effects model is available, i conducted hausman's test in eviews9.0, according to the report of the test, the probability that there is no difference between fixed effects model and random effects model is shown to be nearly $100 \%$. Therefore, $\mathrm{i}$ have strong evidences that it is reasonable to choose a random effects model.

(2) Test for endogeneity of $\log \left(\right.$ wage $\left._{i t}\right)$. To make sure that log(wageit) is endogenous, i conducted test for endogeneity in eviews9.0 and got the estimated residual of the reduced form equation. Then $\mathrm{i}$ put the estimated residual into the structural equation and tested for its significance. According to the report in eviews9.0, the estimated residual is statistically significant with a 4.06 t-statistic, besides, its $95 \%$ confidence interval is [0.29, 0.84], indicating that zero is obviously excluded from the confidence interval. Therefore, we can conclude that log(wageit) is endogenous and instrument variables are needed.

(3) Test for the correlation between endogenous variable $\log \left(w_{a g} e_{i t}\right)$ and instrument variable consumption $_{\text {it. }}$ To make sure that consumption ${ }_{\text {it }}$ is a qualified instrument variable, i made a regression that consumption ${ }_{i t}=\beta_{0}+\beta_{1} \log$ (wage ${ }_{i t}$ ) and got that $\beta_{1}$ is statistically significant with a 14.43 t-statistic, besides, its 95\% confidence interval is [8491, 11170], indicating that zero is obviously excluded from the confidence interval. Therefore, we can conclude that there is considerably high correlation between endogenous variable $\log \left(\right.$ wage $\left._{\text {it }}\right)$ and instrument variable consumption ${ }_{\text {it }}$, in addition, in the theoretical section, $i$ have explained that consumption ${ }_{\text {it }}$ is uncorrelated with the dependent variable $\log \left(\right.$ valueadd $\left._{i t}\right)$. As a result, consumption ${ }_{i t}$ is proved to be a good instrument variable for $\log \left(\right.$ wage $_{\text {it }}$ ).

(4) F-test for overall significance of independent variables. According to the report in eviews9.0, the f-statistic for all the independent variables included is 481.817, indicating that all the independent variables are jointly significant and the regression model makes sense.

(5) In consideration of heteroskedasticity, all the standard errors reported in this paper are heteroskedasticity-robust standard errors. 
Then, based on the empirical study, the interpretation of regression results are presented as follow:

(1) The capability of research and development.As shown significantly, holding other variables fixed, if the amount of patent authorization rises by $1 \%$, the value-added in processing trade is expected to increase by $0.084 \%$. Therefore, the capability of $R \& D$ is positively correlated with value-added in processing trade, which is consistent with the theoretical analysis.

(2) The amount of foreign direct investment. As shown significantly, if the amount of foreign direct investment rises by $1 \%$, the value-added in processing trade is expected to increase by $\left[0.257-0.113^{*} \log\right.$ (TFPit)]\%. Therefore, if $\log$ (TFPit) $<2.27$, which is TFPit $<9.68$ billion, the amount of FDI should be positively correlated with value-added in processing trade, which is consistent with the theoretical analysis. However, if $\log$ (TFPit) $>2.27$, which is TFPit $>9.68$ billion, the amount of FDI turns out to be negatively correlated with value-added in processing trade, which is opposite to the theoretical analysis.

As for the reasons behind, I think that the results are in accordance with the real world. On one hand, for developing provinces with relatively low total factor productivity, the marginal technology-spillover effects from multinational firms to local firms should be relatively large, thus FDI has a positive impact on processing trade. On the other hand, for developed provinces with high total factor productivity, the marginal technology-spillover effects from multinational firms to local firms would become smaller and smaller, in contrast, because the number of firms increases when multinational firms enter the domestic markets, the competition among firms would become stronger and stronger, which is to say, this time the crowd-out effects from multinational firms to local firms begin to dominate the technology-spillover effects, thus FDI turns out to have a negative impact on processing trade. As a result, just as shown in the regression, the higher the productivity of a province is, the less the positive effects of FDI on processing trade are, and the positive effects drop down to negative ones when productivity gets high enough.

(3) The technological level. As shown significantly, if the total factor productivity rises by $1 \%$, the value-added in processing trade is expected to increase by [1.033-0.113* $\log$ (FDIit)]\%. Therefore, if $\log$ (FDIit) $<9.14$, which is FDlit $<9321$ billion (as is in the real world), the technological level should be positively correlated with value-added in processing trade, which is consistent with the theoretical analysis.

(4) The amount of labor costs. As shown significantly, holding other variables fixed, if the average annual wage of employees rises by $1 \%$, the value-added in processing trade is expected to increase by $0.327 \%$. Therefore, the amount of labor costs is positively correlated with value-added in processing trade according to the empirical analysis.

(5) The accumulation of human capital

As shown significantly, holding other variables fixed, if the total amount of senior high school graduates rises by $1 \%$, the value-added in processing trade is expected to increase by $0.479 \%$. Therefore, the accumulation of human capital is positively correlated with value-added in processing trade, which is consistent with the theoretical analysis.

(6) The development of transportation. As shown significantly, holding other variables fixed, if the total mileage of highway and railway rises by ten-thousand kilometers, the value-added in processing trade is expected to increase by $1.0 \%$. Therefore, the development of transportation is positively correlated with value-added in processing trade, which is consistent with the theoretical analysis.

(7) The spatial differences. As shown significantly, holding other variables fixed, compared with provinces in the western part of China, the value-added of processing trade in provinces in the middle part of China is expected to be $36.3 \%$ higher, and the value-added of processing trade in provinces in the eastern part of China is expected to be $80.8 \%$ higher. Therefore, the spatial difference among provinces in China is correlated with their value-added in processing trade, which is consistent with the theoretical analysis and the real situation.

Furthermore, there will be inevitably omitted variable bias in the model because some data are unable to get and some variables are unable to be measured by data. For example, the specific policy on the development of processing trade in each province should be different, which would apparently 
influence the annual value-added of processing trade in a province. As a result, further studies are needed to deal with the problem mentioned above.

\section{Conclusion}

From theoretical analysis and empirical research, we can prove that the capability of research and development, the amount of foreign direct investment, technological level, the amount of labor costs, the accumulation of human capital, the development of transportation and the spatial differences are crucial components that significantly influence the development of processing trade in China. Based on the findings above, several policy recommendations could be made as follow:

(1) Processing trade enterprises should concentrate on self-dependent innovation instead of imitation, increasing the value-added in processing trade rather than just revenue.

(2) Bring in foreign direct investment selectively, especially welcome those FDI with high technology and high value-added.

(3) Encourage the development of high-tech industries in processing trade, such as giving them some financial support.

(4) Increase the accumulation of human capital and the development of transportation and other related infrastructures.

(5) Encourage those middle and western provinces to actively undertake the industrial transfer from abroad or eastern regions according to their own comparative advantages, accelerating the establishment of a unified processing trade market in China.

\section{References}

[1] Zeng Gui. Institutional Study of Transformation Upgrading of Processing Trade [J]. Finance \& Economics, 2011(2): 84-90.

[2] Zhang Qinglin, Chen Wanling. Foreign Investment, Domestic R\&D and Processing Trade UpgradingAn Empirical Analysis Based on Panel Data [J]. International Economics and Trade Research, 2011, 27(7): 4-9.

[3] Zhang Ming, Hu Bing. An Empirical Study on Processing Trade Appreciation Rate [J]. Journal of International Trade, 2010(4): 25-31.

[4] Lv Yue, Liu Zhiyang, Lv Yunlong. The Duration of GVC Embedment and Decisive FactorsEvidence from China [J]. The Journal of Quantitative \& Technical Economics, 2017(6): 37-53.

Chart 1: Data source and first5\&last5 observation

\begin{tabular}{|c|c|c|c|c|c|c|c|c|c|c|c|}
\hline $\begin{array}{c}\text { City } \\
\text { Year }\end{array}$ & $\begin{array}{c}\text { Beijing } \\
2003\end{array}$ & $\begin{array}{c}\text { Beijing } \\
2004\end{array}$ & $\begin{array}{c}\text { Beijing } \\
2005\end{array}$ & $\begin{array}{c}\text { Beijing } \\
2006\end{array}$ & $\begin{array}{c}\text { Beijing } \\
2007\end{array}$ & $\begin{array}{c}\text { Fujian } \\
2011\end{array}$ & $\begin{array}{c}\text { Fujian } \\
2012\end{array}$ & $\begin{array}{c}\text { Fujian } \\
2013\end{array}$ & $\begin{array}{c}\text { Fujian } \\
2014\end{array}$ & $\begin{array}{c}\text { Fujian } \\
2015\end{array}$ & Data Source \\
\hline Lvalueadd & 7.17 & 7.38 & 7.61 & 7.69 & 7.82 & 9.11 & 9.22 & 9.33 & 9.43 & 9.47 & $\begin{array}{c}\text { China's customs statistical } \\
\text { yearbook }\end{array}$ \\
\hline Lpatent & 9.01 & 9.1 & 9.22 & 9.32 & 9.61 & 9.99 & 10.3 & 10.5 & 10.5 & 11 & $\begin{array}{c}\text { China's scientific research } \\
\text { statistical yearbook }\end{array}$ \\
\hline LFDI & 6.13 & 6.27 & 6.4 & 6.54 & 6.77 & 7.22 & 7.28 & 7.35 & 7.45 & 7.58 & China statistical yearbook \\
\hline LTFP & 1.11 & 1.17 & 1.57 & 1.61 & 1.66 & 1.71 & 1.64 & 1.61 & 1.6 & 1.58 & China statistical yearbook \\
\hline Lwage & 9.99 & 10.1 & 10.2 & 10.4 & 10.5 & 10.3 & 10.5 & 10.7 & 10.8 & 10.9 & China statistical yearbook \\
\hline Lgraduate & 10.9 & 11.1 & 11.2 & 11.2 & 11.2 & 12.3 & 12.3 & 12.3 & 12.3 & 12.2 & China statistical yearbook \\
\hline transport & 1.55 & 1.57 & 1.58 & 2.16 & 2.18 & 9.44 & 9.69 & 10.2 & 10.3 & 10.7 & China statistical yearbook \\
\hline
\end{tabular}


Chart 2: Data description

\begin{tabular}{|c|c|c|c|c|c|c|c|c|}
\hline Variable & Type & Scaling & Max & Min & $\begin{array}{l}\text { Num. } \\
\text { Obs. }\end{array}$ & Mean & $\begin{array}{l}\text { Std. } \\
\text { Dev. }\end{array}$ & $\begin{array}{l}\text { Expected } \\
\text { Sign }\end{array}$ \\
\hline $\log \left(\right.$ valueadd $\left._{\text {it }}\right)$ & Dependent & $\ln$ (billion) & 10.39 & 3.87 & 403 & 8.19 & 1.22 & \\
\hline $\log \left(\right.$ patent $\left._{\text {it }}\right)$ & Exogenous & $\ln$ (unit) & 12.50 & 2.77 & 403 & 8.65 & 1.78 & + \\
\hline $\log \left(\mathrm{FDI}_{\mathrm{it}}\right)$ & Exogenous & $\ln$ (billion) & 8.96 & 1.19 & 403 & 5.64 & 1.58 & + \\
\hline $\log \left(\mathrm{TFP}_{\mathrm{it}}\right)$ & Exogenous & $\ln$ (billion) & 2.29 & 0.84 & 403 & 1.57 & 0.22 & + \\
\hline $\begin{array}{l}\log \left(\mathrm{FDI}_{\mathrm{it}}\right)^{*} \\
\log \left(\mathrm{TFP}_{\mathrm{it}}\right)\end{array}$ & Interaction & $\ln ^{2}$ (billion) & 20.18 & 1.38 & 403 & 9.18 & 3.64 & unknown \\
\hline $\log \left(\right.$ wage $\left._{\text {it }}\right)$ & Endogenous & $\ln$ (yuan) & 11.54 & 7.81 & 403 & 10.12 & 0.63 & unknown \\
\hline $\log \left(\right.$ graduate $\left._{\text {it }}\right)$ & Exogenous & $\ln$ (unit) & 13.52 & 8.70 & 403 & 12.04 & 0.94 & + \\
\hline transport ${ }_{i t}$ & Exogenous & ten-thousand kilometers & 32.00 & 0.67 & 403 & 11.70 & 7.13 & + \\
\hline east $_{i}$ & Dummy & 0 or 1 & 1.00 & 0.00 & 403 & 0.38 & 0.48 & + \\
\hline $\operatorname{mid}_{\mathrm{i}}$ & Dummy & 0 or 1 & 1.00 & 0.00 & 403 & 0.38 & 0.48 & + \\
\hline consumption $_{\text {it }}$ & Instrument & yuan & 48750 & 4933 & 403 & 15147 & 7577 & \\
\hline
\end{tabular}

Additionally, to depict the correlation between dependent variable and independent variables after partialling out, I obtain scatter plots between the residual of each independent variable $r_{i}$ and the

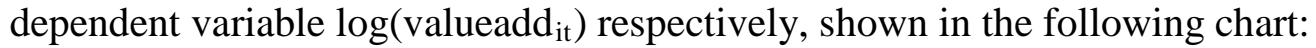

Chart 3: (partialling out) Scatter plots between residual $r_{i}$ and $\log \left(\right.$ valueadd $\left._{i t}\right)$

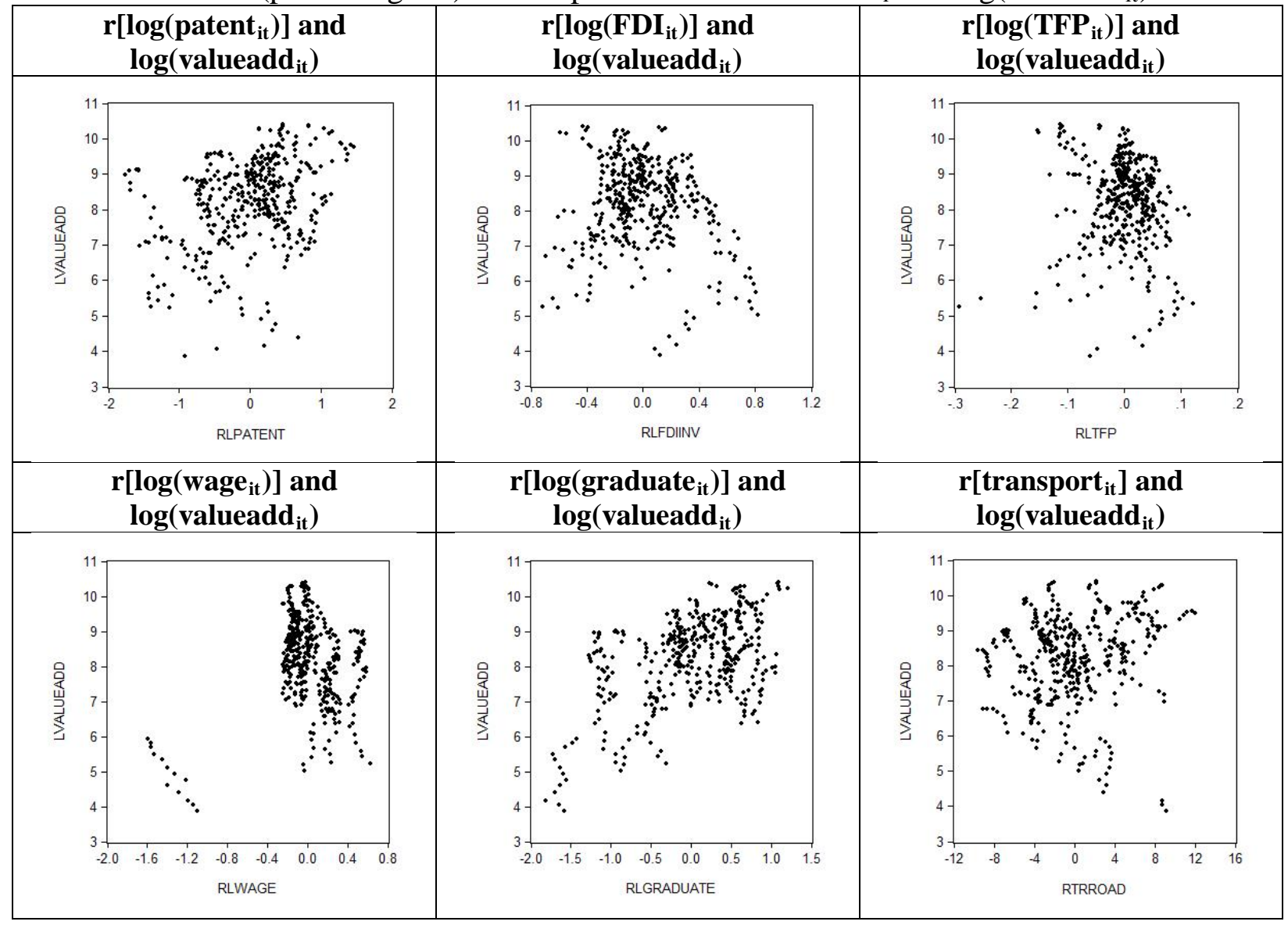


Chart 4: Original output from Eviews

Dependent Variable: LVALUEADD Method: Panel Two-Stage EGLS (Cross-section random effects)

Sample: 20032015 Periods included: 13 Cross-sections included: 31

Total panel (balanced) observations: 403 Swamy and Arora estimator of component variances White diagonal standard errors \& covariance (d.f. corrected) Instrument specification:

LPATENT LFDIINV LTFP LTFP_LFDI CONSUME LGRADUATE TRROAD EAST MID C

\begin{tabular}{crrrr} 
Variable & Coefficient & Std. Error & t-Statistic & Prob. \\
\hline \hline LPATENT & 0.084499 & 0.020540 & 4.113921 & 0.0000 \\
LFDIINV & 0.256938 & 0.057011 & 4.506814 & 0.0000 \\
LTFP & 1.032984 & 0.194385 & 5.314108 & 0.0000 \\
LTFP_LFDI & -0.113174 & 0.027222 & -4.157435 & 0.0000 \\
LWAGE & 0.326819 & 0.086989 & 3.757024 & 0.0002 \\
LGRADUATE & 0.478527 & 0.039519 & 12.10882 & 0.0000 \\
TRROAD & 0.010141 & 0.002988 & 3.393843 & 0.0008 \\
EAST & 0.808112 & 0.135550 & 5.961709 & 0.0000 \\
MID & 0.363438 & 0.099925 & 3.637108 & 0.0003 \\
C & -4.224452 & 0.929545 & -4.544642 & 0.0000
\end{tabular}

